\title{
Characterization and Genetic Variation of Sugarcane Streak Mosaic Virus, a Poacevirus Infecting Sugarcane in Thailand
}

\author{
Paweena Kasemsin ${ }^{1,2}$, Pissawan Chiemsombat ${ }^{3}$ \& Ratchanee Hongprayoon ${ }^{1,2,3}$ \\ ${ }^{1}$ Center for Agricultural Biotechnology, Kasetsart University, Kamphaeng Saen Campus, Nakhon Pathom 73140 \\ Thailand \\ ${ }^{2}$ Center of Excellence on Agricultural Biotechnology: (AG-BIO/PERDO-CHE), Bangkok, Thailand \\ ${ }^{3}$ Department of Plant Pathology, Faculty of Agriculture at Kamphaeng Saen, Kasetsart University, Kamphaeng \\ Saen Campus, Nakhon Pathom, Thailand \\ Correspondence: Pissawan Chiemsombat, Department of Plant Pathology, Faculty of Agriculture at Kamphaeng \\ Saen, Kasetsart University, Kamphaeng Saen Campus, Nakhon Pathom 73140, Thailand. Tel: 6681-4132-222. \\ E-mail: agrpwc@ku.ac.th
}

Received: October 23, 2015

Accepted: December 23, 2015

Online Published: February 2, 2016

doi:10.5539/mas.v10n4p137

URL: http://dx.doi.org/10.5539/mas.v10n4p137

\begin{abstract}
Sugarcane leaves showing yellow streak mosaic symptoms were observed in farmers' fields in Kamphaeng Saen, Nakhon Pathom province, during disease surveys conducted in 2010. Diagnosis of symptomatic leaf samples by RT-PCR for Sugarcane mosaic potyvirus failed, but it revealed the presence of Sugarcane streak mosaic virus (SCSMV). SCSMV-infected sugarcane, designated as THA-NP3, was subjected to RNA extraction and RT-PCR-based viral gene cloning and sequencing. The complete genome of THA-NP3 (JN163911) contained 9,781 nucleotides, excluding $3^{\prime}$ poly (A) tail which encoded a polyprotein of 3,130 amino acid residues. Protein sequence analysis indicated nine putative cleavage sites that yielded ten functional proteins namely P1, HC-Pro, P3, 6K1, CI, 6K2, NIa-VPg, NIa-Pro, NIb and CP, and an additional frameshifted PIPO protein. Sequence alignment revealed that THA-NP3 shared 97.84\% nucleotide identity with JP2 from China and 81.39-97.78\% identities to other recorded SCSMV sequences. Surveys for streak mosaic disease were conducted from 2010 to 2014 at major sugarcane growing areas in five provinces, Nakhon Pathom, Kanchanaburi, Nakhon Ratchasima, Khon Kaen and Udon Thani, and among germplasm collections. The percentages of the infected samples ranged from $43.48-90.91 \%$ and $54.17-100 \%$ in collected farmers and germplasm fields, respectively. Genetic diversity based on coat protein (CP) coding sequences of 58 Thai SCSMV isolates showed $86.17-100 \%$ nucleotide identities among them and 85.70-99.29\% identities to isolates from other countries. Phylogenetic analysis of CP sequences indicated two major clusters of virus variants, one in cropping fields and another in germplasm fields. Genetic variations of SCSMV isolates were consistently indicated according to recombination events detected in CP coding regions. These findings represent essential knowledge and should be utilized to improve the SCSMV resistance of sugarcane varieties.
\end{abstract}

Keywords: Sugarcane streak mosaic virus, Potyviridae, Poacevirus, polyprotein, coat protein sequence

\section{Introduction}

Sugarcane (Saccharum officinarum L.) is a valuable crop for the sugar industry and is widely cultivated in Brazil, India, China, Thailand and Pakistan. In Thailand, it is largely cultivated in central, western and northeastern areas such as Nakhon Sawan, Kanchanaburi, Nakon Ratchasima, Khon Kaen and Udon Thani provinces. The major commercial sugarcane varieties cultivated in Thailand include LK92-11, K76-4, K84-200, UT1, UT3, UT8, SP50 and KK3 (Thongpaiyai, Wongpraneekul, \& Chatwachirawong, 2012). Major constraints of sugarcane production in Thailand are sugarcane white leaf disease caused by phytoplasma, sugarcane red rot disease caused by Colletotrichum falcatum, and mosaic disease caused by Sugarcane mosaic virus (SCMV). During surveys conducted from 2002 to 2004, the diagnosis of symptomatic sugarcane plants showing mosaic, yellow streak, chlorotic or necrotic streak, chlorotic mild mottle or mild mosaic revealed the presence of SCMV in many sugarcane production fields (Gemechu, 2004). In 2005, a distinct virus species, namely Sugarcane streak mosaic virus (SCSMV) was detected in sugarcane and sorghum plants which showed typical mosaic symptoms as those caused by SCMV but failed to react with the antisera against SCMV, SrMV and JGMV (Chatenet et al., 2005). 
SCSMV was reported for its devastating effects in Asia, including India (Viswanathan et al., 2008), Pakistan, Sri Lanka, Vietnam, Thailand (Chatenet et al., 2005), China (Li et al., 2011) and Indonesia (Damayanti \& Putra, 2011). The identified hosts of SCSMV under natural condition are poaceae plants including sugarcane, maize, sorghum and Egyptian crowfoot grass (Dactylactonium aegypticum) (Hema, Joseph, Gopinath, Sreenivasulu, \& Savithri, 1999; Putra, Kristini, Achadian, \& Damayanti, 2014; Srinivas, Subba Reddy, Ramesh, Lava Kumar, \& Sreenivasulu, 2010).

The SCSMV virion is flexuous rod, size of $890 \times 15 \mathrm{~nm}$, and comprises a positive sense single stranded RNA genome of $9.8 \mathrm{~kb}$, characteristic of members in the family Potyviridae (Hema, Sreenivasulu, \& Savithri, 2002). The viral genome contains a single open reading frame (ORF) which encodes a polyprotein of 3130 amino acid residues. The polyprotein is processed by the viral protease yielding ten different proteins, namely P1, HC-Pro, P3, 6K1, CI, 6K2, NIa-VPg, NIa-Pro, NIb and CP. The first published complete genome sequence of SCSMV which was isolated from sugarcane in Pakistan, SCSMV-PAK: GQ388116, contained 9782 nucleotides (nts), excluding 3' Poly (A) tail (Xu, Zhou, Xie, Mock, \& Li, 2010). Sequence comparison and a phylogenetic tree of the complete genome revealed that SCSMV was a distinct group from those of other genus in the family Potyviridae, and has been recently named Poacevirus (Xu et al., 2010; ICTV: www.ictvonline.org). More isolates of SCSMV and their complete genome sequences were reported from China (Li et al., 2011) and India (Parameswari, Bagyalakshmi, Viswanathan, \& Chinnaraja, 2013). The study on genetic variability of SCSMV has been investigated using the analysis of CP (He et al., 2013), P1 (He et al., 2013) and HC-Pro (Bagyalakshmi et al., 2012) coding regions. The comparison of these genes revealed high variation among different SCSMV isolates resulting from recombination (Bagyalakshmi et al., 2012; He et al., 2013). In Thailand, the presence and distribution of SCSMV in Thailand and genetic variations of the existing isolates still have not been recorded so far.

In this study, sugarcane leaves showing yellow streak mosaic symptom in farmers' fields were diagnosed, and the causal virus was identified. A full length genome of Thai isolate of SCSMV was reconstructed by RT-PCR amplification and its nucleotide sequence was determined for the first time. Disease surveys were conducted, samples were collected for viral gene amplification, and genetic variations among Thai SCSMV isolates were analyzed based on coat protein $(\mathrm{CP})$ coding region.

\section{Method}

\subsection{Disease Survey and Sample Collection}

Sugarcane disease surveys for SCSMV infection were performed from 2010 to 2014 in 5 provinces of the major sugarcane growing areas of Thailand (Nakhon Pathom, Kanchanaburi, Udon Thani, Khon Kaen and Nakhon Ratchasima). Virus-like symptomatic sugarcane samples, particularly young mosaic leaves, were collected and kept in sealed plastic bags. Samples were also collected from sugarcane germplasm collection fields, belonging to Kasetsart University, in Nakhon Pathom and Kanchanaburi provinces. More samples from the germplasm collection fields in Suphan Buri province were kindly provided by the Department of Agriculture, Ministry of Agriculture and Cooperatives.

\subsection{Detection of SCSMV by Direct Antigen Coating ELISA (DAC-ELISA)}

Collected sugarcane leaf tissues were diagnosed for the presence of SCSMV by DAC-ELISA, using the locally produced antiserum raised against the purified SCSMV (Kasemsin, Chiemsombat, \& Hongprayoon, 2011). Briefly, one gram of leaf tissue was ground in a plastic bag containing $1 \mathrm{ml}$ of the extraction buffer (PBS, $\mathrm{pH} 7.4$, $0.2 \%$ sodiumdiethyldithiocarbamate). The homogenate was diluted at 1:10 in coating buffer. A $100 \mu \mathrm{l}$ of the diluted plant extract was loaded in each well of a microtiter plate and incubated overnight at $4^{\circ} \mathrm{C}$. The protocol as described by Chiemsombat, Prammanee, \& Pipattanawong (2014) was followed except for SCSMV antiserum was diluted at 1:500 and incubated at $37^{\circ} \mathrm{C}$ for $1 \mathrm{~h}$.

\subsection{Viral Genome Amplification and Analysis}

\subsubsection{Primer Design}

The specific primers used in this study (Table 1) for amplification of the SCSMV complete genome were designed based on the alignment of the complete genome sequence of SCSMV-PAK: GQ388116 and other partial SCSMV sequences recorded in GenBank (Y17738, EU650179, EF088799, EU650178, EU883391, EF088797, DQ421788, AM920686, AM920685, AB563503, GQ386845, GQ386843, GQ386844, Y17738, AY193783, AY189681). Two specific primers for amplification of the entire coat protein gene were also designed (Table 1). 
Table 1. List of specific primers for amplification of SCSMV genes and the overlapping sequences of SCSMVTHA complete genome

\begin{tabular}{|c|c|c|c|}
\hline Primer pair & Nucleotide sequence $\left(5^{\prime}\right.$ to $\left.3^{\prime}\right)$ & Product size $(\mathrm{bp})$ & Annealing temp $\left({ }^{\circ} \mathrm{C}\right)$ \\
\hline SCS-F2 & GCCAAGGCAAAGCAGATGATGAG & 881 & 55 \\
\hline A-d-T-R2 & TTTTTTTTTTTTTTTTTCCTCCN & & \\
\hline SCS-F3 & AGAGACAAGCTGGGTCACACTG & 1129 & 57 \\
\hline SCS-R3 & CGTATTGATGCGGCCGATGAAG & & \\
\hline SCS-F4 & CTGGAATGATGCAGTATGCGCTC & 1043 & 57 \\
\hline SCS-R4 & GTCCGCGTCAATGAACTTCCAG & & \\
\hline SCS-F5 & AAGCGCCGAACACACGCTCGTG & 1096 & 58 \\
\hline SCS-R5 & TCACTACCCGAGCTGCCGAATG & & \\
\hline SCS-F6 & GCCACAACTTCCAАTCCCATTC & 755 & 57 \\
\hline SCS-R6 & TTCCGGCATTCTTCTTGGCG & & \\
\hline SCS-F7 & AGCTACACCACCAGGAGCACG & 1043 & 57 \\
\hline SCS-R7 & GCGCTTCAGACGTTGACAATCG & & \\
\hline SCS-F8 & GACGACACAACAAGGTTAGCGC & 1067 & 55 \\
\hline SCS-R8 & ATGAGTATACGCCCTCCGTTTG & & \\
\hline SCS-F9 & GGAGGTGTGTTACCAGATTTGCG & 1003 & 57 \\
\hline SCS-R9 & CCGTCTTTCCTTGTGCGTGGTG & & \\
\hline SCS-F10 & CAGATCCTGAACGAAATTGCACG & 1102 & 57 \\
\hline SCS-R10 & CTGCAATATCGGGATGATTCCTC & & \\
\hline SCS-F11 & CGACAACACTGGTGAAGTTGAAG & 1183 & 57 \\
\hline SCS-R11 & CGATAGTGGTTGGCTAGCGGTG & & \\
\hline SCS-F12 & AAATGTAAT TTCAAATTGACTAC & 872 & 57 \\
\hline SCS-R12 & CATTAGTTCGCATAATCACACG & & \\
\hline SCS-NIb-CP:F & TTGGTGGAGCAAGCACACAG & 1094 & 61 \\
\hline SCS-NIb-CP:R & CGGTCAGGCAACTACCATCA & & \\
\hline
\end{tabular}

Note. $\mathrm{N}$ in the A-d-T-R2 represents the regenerated bases (A, T, G and C).

\subsubsection{Total RNA Extraction and Reverse Transcription Polymerase Chain Reaction (RT-PCR)}

Total RNA was extracted from the sugarcane leaf tissues using TLES buffer $(100 \mathrm{mM}$ Tris-HCl, $\mathrm{pH}$ 8.0, $100 \mathrm{ml}$ $\mathrm{LiCl}, 10 \mathrm{mM}$ EDTA, $\mathrm{pH}$ 8.0, 1\% SDS, 0.1\% sodium sulphite) according to Verwoerd, Dekker, \& Hoekema (1989). The viral cDNA was synthesized using a SuperScript III cDNA synthesis kit (Invitrogen, USA) following the manufacturer's protocol. This cDNA was added to PCR reactions for synthesis of the 11 overlapping fragments covering the whole genome of SCSMV, using our designed 11 primer pairs (Table1).

PCR reaction consisted of $1 \mathrm{X}$ PCR buffer, $0.4 \mathrm{mM}$ dNTP mix, $2 \mathrm{mM} \mathrm{MgSO}_{4}, 10 \mathrm{pmol}$ of each primer, $1 \mathrm{U}$ of Hi-Fidelity Taq (Invitrogen, USA), $1 \mu \mathrm{l}$ of cDNA and RNase-free water to adjust the total volume to $25 \mu \mathrm{l}$. The reaction was started with the initial step of denaturation at $94^{\circ} \mathrm{C}$ for $4 \mathrm{~min}$, followed by 30 cycles of denaturation at $98^{\circ} \mathrm{C}$ for $30 \mathrm{sec}$, annealing for $1 \mathrm{~min}$ at temperature according to the annealing temperature of each primer pair (Table 1), extension at $68^{\circ} \mathrm{C}$ for $1-2$ min according to the length of each overlapped sequence $(1 \mathrm{~kb} / 1 \mathrm{~min})$ and 1 cycle of the final extension at $68^{\circ} \mathrm{C}$ for $7 \mathrm{~min}$. RT-PCR products were analyzed on $0.8 \%$ agarose gel electrophoresis.

\subsubsection{Viral Gene Cloning and Sequencing}

The RT-PCR products obtained from each primer were purified using a PCR/Gel purification kit following the manufacturer's protocol (Favorgen Biotech Corp, Taiwan) and separately cloned into the pGEM-T cloning vector (Promega, USA). The selected clones with a viral gene insert were subjected for sequencing in both directions at BioDesign, Thailand.

\subsubsection{Viral Genome Sequence Assembly and Analysis}

The presence of sections of the SCSMV was verified using nucleotide blast on sequenced inserts (www.ncbi.nlm.nih.gov/BLAST) and then assembled from $5^{\prime}$ to $3^{\prime}$ in BioEdit, version 7.2.5 (http://www.mbio.ncsu.edu/). The full length nucleotide sequences of the complete genome were initially confirmed by searching for an ORF by using ORFinder (http://www.ncbi.nlm.nih.gov). The putative cleavage sites of the deduced proteins on the polyprotein were determined by comparing the potential cleavage sites with those of SCSMV isolates, PAK: GQ388116, TPT: GQ246187, ID: JF488066, JP1: JF488064, JP2: JF488065 and IND671: JN941985. 


\subsection{Amplification, Cloning and Sequencing of the CP Coding Region}

The CP coding region of SCSMV was amplified by RT-PCR using a CP specific primer pair, SCS-NIb-CP: F and SCS-NIb-CP: R (Table 1). The viral cDNA was synthesized from total RNA using ReverTraAce (TOYOBO, Japan) following the manufacturer's protocol.

The PCR reaction consisted of 1X PCR buffer, $0.4 \mathrm{mM}$ dNTP mix (TOYOBO, Japan), $2 \mathrm{mM} \mathrm{MgSO}_{4}, 10$ pmol of each primer, $1 \mathrm{U}$ of KOD-Plus-Neo (TOYOBO, Japan), $1 \mu \mathrm{l}$ of cDNA and RNase-free water to adjust the total volume to $25 \mu \mathrm{l}$. The amplification cycle was the same as described above (2.3.2) except that the annealing temperature was $61^{\circ} \mathrm{C}$ for $1 \mathrm{~min}$. The RT-PCR products were analyzed by $0.8 \%$ agarose gel electrophoresis and submitted to direct sequencing in both directions (SolGent, South Korea). Some selected purified products were cloned into pGEM-T cloning vectors (Promega, USA), and the plasmids containing gene inserts were sequenced in both directions (SolGent, South Korea).

\subsection{Sequence Analysis and Phylogenetic Tree of the CP Coding Regions}

The nucleotide (nt) and amino acid (aa) sequences of the CP coding regions among SCSMV isolates used in this study (Table 2) were analyzed by using clustalW in the CLC program package (http://www.clcbio.com). Pairwise comparisons were also created using the CLC program. The phylogenetic relationships were analyzed by using MEGA6 program (Tamura, Stecher, Peterson, Filipski, \& Kumar, 2013).

\subsection{Recombination Analysis of the CP Coding Regions}

The recombination events of SCSMV isolates used in this study (Table 2) were detected using RDP4 (Martin, Murrell, Golden, Khoosal, \& Muhire, 2015). The detection algorithms used in this study were the automated RDP, GENECONV, Chimaera, MaxChi, BOOTSCAN, SISCAN, 3Seq and LARD which are implemented in the RDP4 program (version 4.50 ) with default setting.

\subsection{Networks Analysis Using Splitstree}

Phylogenetic networks of the CP coding regions among SCSMV isolates (Table 2) were created by using SplitsTree4.11 (Huson \& Bryant, 2006). The alignment file obtained from clustalW was used for construction of the phylogenetic network using median network in SplitsTree4.11.

\section{Results}

\subsection{Incidence of SCSMV in Surveyed Sugarcane Fields}

In this survey, diseased sugarcane plants showed typical symptoms of yellow streak mosaic, especially on young leaves (Figure 1a-b), while older leaves showed mild symptoms. Two hundred and thirty-three sugarcane leaf samples were collected from 14 farmers' fields of which 153 samples tested positive by DAC-ELISA. Some sample obtained from older leaves had positive reactions by DAC-ELISA but the absorbance $\left(\mathrm{A}_{405}\right)$ values (0.277-0.339) were lower than in younger leaves. Therefore, the presence of SCSMV in some selected samples was confirmed by RT-PCR. This survey indicated that SCSMV is widespread and was present in all collected fields in Nakhon Pathom, Kanchanaburi, Udon Thani, Khon Kaen and Nakhon Ratchasima provinces (Figure 2). The percentage of the infected samples of all collected fields ranged from 43.48-90.91\% (Figure 2).

In three fields containing germplasm collections, 138 samples from 73 sugarcane varieties were collected. Of these, 91 samples obtained from 50 varieties indicated positive reactions by DAC-ELISA. The percentage of positive reaction within varieties ranged from $54.17-100 \%$ (Figure 2). In a subsequent study, we selected 36 isolates from different farmers' fields in 5 provinces and 22 isolates from fields containing germplasm collections to examine the genetic variation based on sequence analysis of the viral CP gene. All selected isolates yielded the expected 1094 bp RT-PCR product, from which an isolate from Kamphaeng Saen District, Nakhon Pathom Province, designated as THA-NP3 (Figure 1a) was subjected to full length genome sequencing.

Table 2. The CP gene of Thai SCSMV isolates from different surveyed areas used for comparison and phylogenetic tree analysis

\begin{tabular}{clllll}
\hline No. & $\begin{array}{l}\text { Isolates } \\
\text { name }\end{array}$ & $\begin{array}{l}\text { Surveyed } \\
\text { areas }\end{array}$ & $\begin{array}{l}\text { Collection } \\
\text { year }\end{array}$ & $\begin{array}{l}\text { Sugarcane } \\
\text { varieties }\end{array}$ & $\begin{array}{l}\text { GenBank } \\
\text { accession no. }\end{array}$ \\
\hline 1 & FDT1 & Kanchanaburi & 2012 & Unknown & KP987806 \\
2 & FKB1 & Kanchanaburi & 2012 & Unknown & KP987848 \\
3 & FKB13 & Kanchanaburi & 2012 & Unknown & KP987807 \\
4 & FKB6 & Kanchanaburi & 2012 & Unknown & KP987839 \\
\hline
\end{tabular}




\begin{tabular}{|c|c|c|c|c|c|}
\hline 5 & FSC1 & Kanchanaburi & 2012 & Unknown & KP987820 \\
\hline 6 & $\mathrm{FSC} 2$ & Kanchanaburi & 2012 & Unknown & KP987821 \\
\hline 7 & FSC7 & Kanchanaburi & 2012 & Unknown & KR057207 \\
\hline 8 & FSC8 & Kanchanaburi & 2012 & Unknown & KP987822 \\
\hline 9 & FKPS10 & Nakhon Pathom & 2012 & Unknown & KR057206 \\
\hline 10 & FKPS19 & Nakhon Pathom & 2012 & Unknown & KP987811 \\
\hline 11 & FKPS22 & Nakhon Pathom & 2012 & Unknown & KP987812 \\
\hline 12 & FNP5 & Nakhon Pathom & 2012 & Unknown & KP987813 \\
\hline 13 & FNP-KPS & Nakhon Pathom & 2012 & Unknown & KP987814 \\
\hline 14 & FNS5 & Nakhon Pathom & 2012 & Unknown & KР987819 \\
\hline 15 & FNS4 & Nakhon Pathom & 2012 & Unknown & KP987840 \\
\hline 16 & THA-NP3 & Nakhon Pathom & 2010 & Unknown & JN163911 \\
\hline 17 & FUD9-3 & Udon Thani & 2012 & Unknown & KP987824 \\
\hline 18 & FUD9-5 & Udon Thani & 2012 & Unknown & KP987825 \\
\hline 19 & FUD10-7 & Udon Thani & 2012 & Unknown & KR057211 \\
\hline 20 & FUD10-4 & Udon Thani & 2012 & Unknown & KР987826 \\
\hline 21 & FUD10-12 & Udon Thani & 2012 & Unknown & KP987827 \\
\hline 22 & FUD11-1 & Udon Thani & 2012 & Unknown & KR057212 \\
\hline 23 & FUD11-2 & Udon Thani & 2012 & Unknown & KP987828 \\
\hline 24 & FUD12-3 & Udon Thani & 2012 & Unknown & KP987829 \\
\hline 25 & FUD12-6 & Udon Thani & 2012 & Unknown & KR057213 \\
\hline 26 & FUD12-8 & Udon Thani & 2012 & Unknown & KP987830 \\
\hline 27 & FUD12-9 & Udon Thani & 2012 & Unknown & KP987831 \\
\hline 28 & FUD12-10 & Udon Thani & 2012 & Unknown & KP987804 \\
\hline 29 & FKH8 & Khon Khan & 2012 & Unknown & KP987805 \\
\hline 30 & FKH4-8 & Khon Kaen & 2012 & Unknown & KP987808 \\
\hline 31 & FKH5-1 & Khon Kaen & 2012 & Unknown & KР987809 \\
\hline 32 & FKH5-2 & Khon Kaen & 2012 & Unknown & KP987810 \\
\hline 33 & FNR3-1 & Nakon Ratchasima & 2012 & Unknown & KP987815 \\
\hline 34 & FNR3-4 & Nakon Ratchasima & 2012 & Unknown & KР987816 \\
\hline 35 & FNR3-6 & Nakon Ratchasima & 2012 & Unknown & KP987817 \\
\hline 36 & FNR3-9 & Nakon Ratchasima & 2012 & Unknown & KP987818 \\
\hline 37 & GK88-65 & Nakhon Pathom & 2014 & K88-65 & KP987836 \\
\hline 38 & GK88-87 & Nakhon Pathom & 2014 & K88-87 & KP987837 \\
\hline 39 & GUT6 & Nakhon Pathom & 2014 & UT6 & KP987842 \\
\hline 40 & GUT4 & Nakhon Pathom & 2014 & UT4 & KP987832 \\
\hline 41 & GUT5 & Nakhon Pathom & 2014 & UT5 & KP987841 \\
\hline 42 & GK76-4 & Nakhon Pathom & 2014 & K76-4 & KP987847 \\
\hline 43 & GRT2007-091 & Kanchanaburi & 2014 & RT2007-091 & KP987843 \\
\hline 44 & GRT2003-639 & Kanchanaburi & 2014 & RT2003-639 & KP987844 \\
\hline 45 & GEhaew & Kanchanaburi & 2014 & Ehaew & KP987802 \\
\hline 46 & G03208 & Kanchanaburi & 2014 & 03208 & KP987803 \\
\hline 47 & GUT3 & Kanchanaburi & 2014 & UT3 & KP987834 \\
\hline 48 & G519 & Kanchanaburi & 2014 & 519 & KP987835 \\
\hline 49 & GROC7 & Kanchanaburi & 2014 & ROC7 & KP987846 \\
\hline 50 & G99-2-294 & Kanchanaburi & 2014 & $99-2-294$ & KR057205 \\
\hline 51 & G02-483 & Kanchanaburi & 2014 & $02-483$ & KR057208 \\
\hline 52 & G94-2-106 & Kanchanaburi & 2014 & $94-2-106$ & KR057209 \\
\hline 53 & G95-2-213 & Kanchanaburi & 2014 & $95-2-213$ & KR057210 \\
\hline 54 & GUT10 & Kanchanaburi & 2014 & UT10 & KR057214 \\
\hline 55 & G03041 & Suphan Buri & 2012 & 03041 & KP987845 \\
\hline 56 & GSP50-2 & Suphan Buri & 2012 & SP50-2 & KP987823 \\
\hline 57 & GUT8 & Suphan Buri & 2012 & UT8 & KP987833 \\
\hline 58 & GK92-80 & Suphan Buri & 2012 & K92-80 & KP987838 \\
\hline
\end{tabular}

Note. Isolate No. 1-36 were obtained from farmers field and isolate No. 37-58 were obtained from germplasm collection fields. 


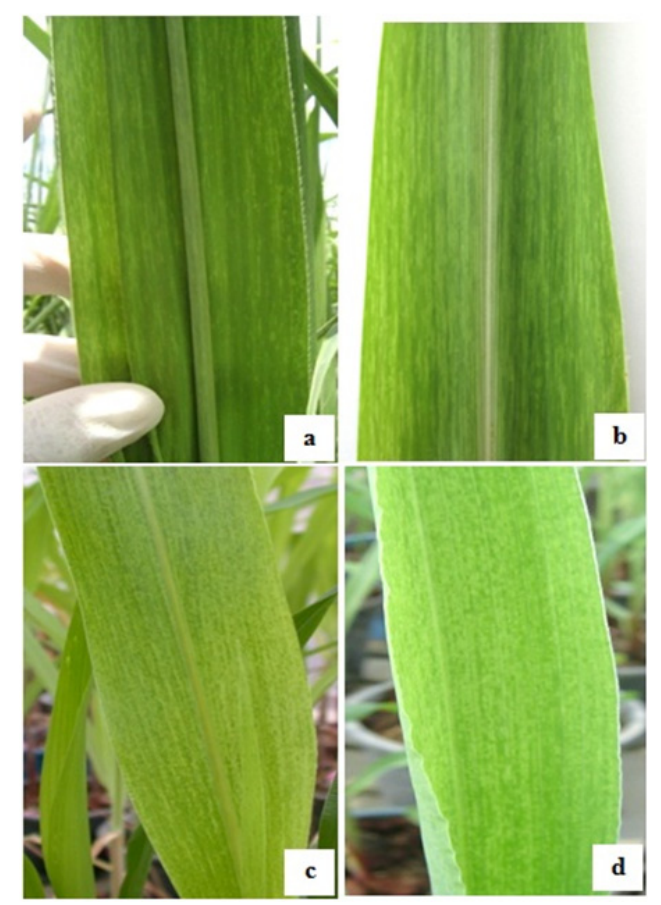

Figure 1. Yellow streak mosaic symptoms on SCSMV infected plants. Sugarcane leaves obtain from the farmer's field in Kamphaeng Saen, Nakhon Pathom, isolate THA-NP3 (a), sugarcane cv. UT8 (b), the inoculated plants, sorghum cv. UT325B at 15 days post-inoculation, dpi (c) and the commercial corn, cv. Tender58 at 5 dpi (d)

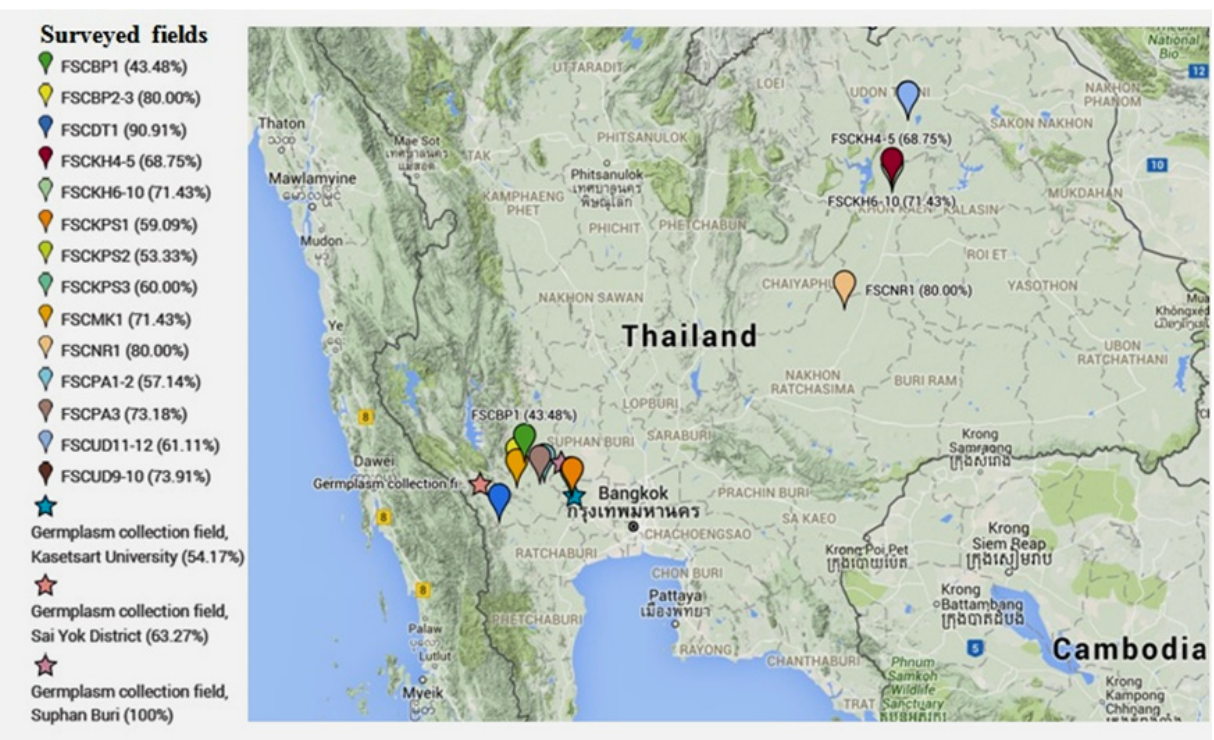

Figure 2. The survey map of streak mosaic disease incidence in farmers (F) and germplasm collection (G) sugarcane fields during 2010 to 2014 in five provinces, including Kanchnaburi (FSCPA1-2, FSCPA3, FSCBP1,

FSCBP2-3, FSCDT1, FSCMK1), Khon Kaen (FSCKH4-5, FSCKH6-10), Nakhon Pathom (FSCKPS1,

FSCKPS2, FSCKPS3), Nakhon Ratchasima (FSCNR1), and Udon Thani (FSCUD9-10, FSCUD11-12). The percentages of the infection rates are shown in brackets for each surveyed fields

\subsection{Genome Characterization of THA-NP3}

The genome of isolate THA-NP3 (JN163911) consisted of $9781 \mathrm{nts}$, excluding the $3^{\prime}$ poly (A) tail. Blast analysis of the complete genome revealed that this virus isolate was homologous to SCSMV isolates recorded in the database. Sequence analysis revealed that the $5^{\prime}$ untranslated region (UTR) consisted of 199 nts. The initiation 
codon AUG (nts 200-202) of the long polyprotein ORF was ended by the termination codon UGA (nts 9591-9593) and was followed by a 3' UTR of 189 nts (Figure 3). The coding region, consisted of 9393 nts, encoded a polyprotein of 3130 amino acid residues with a calculated $\mathrm{Mr}$ of $356.53 \mathrm{kDa}$. This polyprotein had extensive amino acid sequence homology to those of SCSMV polyprotein isolates.

Nine putative cleavage sites of the polyprotein were identified in comparison to the putative sites of SCSMV-PAK polyprotein (Xu et al., 2010) and some others (Figure 3). All cleavage sites of THA-NP3 proteins as well as the positions of the amino acids were similar to those of the SCSMV isolates, PAK, ID, JP1, JP2 and TPT but not IND671. The amino acid sequences of the conserved motifs were slightly different among SCSMV isolates (Figure 3). Thus, the putative 10 functional proteins of THA-NP3 are P1 (41.47 kDa), HC-Pro (54.41 $\mathrm{kDa})$, P3 (37.39 kDa), 6K1 (5.43 kDa), CI (74.82 kDa), 6K2 (5.55 kDa), NIa-VPg (22.47 kDa), NIa-Pro (26.64 $\mathrm{kDa})$, NIb (57.43 kDa) and $\mathrm{CP}(31.07 \mathrm{kDa})$.

The genome sequence of THA-NP3 was analyzed for the presence of Pretty Interesting Potyviridae ORF (PIPO) in the P3 gene with a highly conserved motif, $\mathrm{G}_{1-2} \mathrm{~A}_{6-7}$ similar to the previous report of potyviruses (Chung, Miller, Atkins, \& Firth, 2008). The result revealed that the conserved motif, GGAAAAAAA was found at the nucleotide position 3085-3093 which is similar to that of SCSMV-PAK reported by Xu et al. (2010). The deduced 139 aa of PIPO of THA-NP3 was obtained from $420 \mathrm{bp}$ in the +1 frame at the nucleotide position 3091-3510 as reported by Chandran and Gajjeraman (2015).

The motif scan, using the NCBI-CDD database, of the THA-NP3 polyprotein revealed 19 motifs. The P1 of this virus isolate contained a serine peptidase at the amino acid position 208-312. The peptidase_C6 conserved motif, which is contained in the HC-Pro protein, was found at the amino acid position 684-810. The conserved motif, C-71-X-H (aa 715-787), was found at the C-terminal region of the HC-Pro protein while the conserved motifs associated with aphid transmission were not found. The CI protein was the largest protein among ten functional proteins and contained RNA helicases of superfamily II at the positions 1451-1583. The THA- NP3 VPg protein contained a conserved tyrosine for linking VPg to the 5'-terminus of the viral RNA in the motif L-Y-D-L-D (aa 1988-1992). The NIa protein contained cysteine protease at the amino acid position 2242-2274. The NIb protein contained the conserved motif, D-G-S-R-Y-D (aa 2589-2594) which represented the function for RNA dependent RNA polymerase. The potyvirus coat protein conserved motif was found in the CP protein at the amino acid position 2912-3072. Moreover, the conserved motifs such as Y-X-P-17X-W (aa 2915-2935) and A-X-P-2X-R-2X-M-6X-A (aa 3012-3027) and D-F (aa 3062-3063) were also found in the CP protein, but the DAG motif involved in aphid transmission was not found.

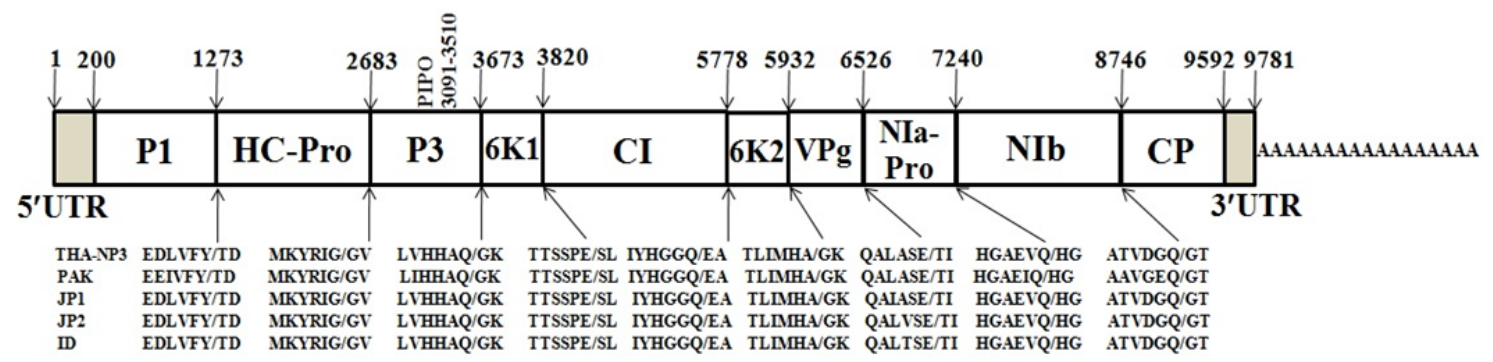

Figure 3. Schematic represents genome organization of Sugarcane streak mosaic virus, an isolate THA-NP3 (JN163911). The 5'UTR (199 nts) and the 3'UTR (189 nts) regions are shown as shaded boxes. The boxes show each of 10 functional proteins. Numbers above the box indicate the nucleotide positions including protein initial codons. The cleavage sites for viral proteinases of each complete genome isolate are indicated below. The PIPO protein is encoded in +1 frame at the nucleotide position 3091-3510. The $3^{\prime}$ poly $\left(\mathrm{A}_{17}\right)$ obtain from the RT-PCR product using the first primer pair (SCS-F2, A-d-T-R2)

\subsection{Comparison of THA-NP3 Complete Genome with Other Genome Isolates}

The comparisons of the complete genome sequences showed that THA-NP3 was very similar to JP2, JP1, ID and TPT isolates with $97.84 \%, 97.78 \%, 97.73 \%$ and $94.80 \%$ nucleotide identities, respectively. It was less similar to PAK and IND671 isolates with $81.83 \%$ and $81.39 \%$ nucleotide identities, respectively (Table 3). The comparison of the polyprotein among seven SCSMV isolates showed that THA-NP3 shared 98.98\% identities with three isolates (JP1, JP2, ID) and 94.38-98.40\% identities with two Indian isolates (TPT, IND671) while it shared 95.27\% identity with PAK. These results suggest that THA-NP3 is clustered in the same group with JP1, JP2, ID and TPT isolates which separated from PAK and IND671 isolates. Moreover, THA-NP3 polyprotein showed 52.40\% 
nt and 50.38\% aa identities with TriMV.

The NIb protein was more conserved protein among poaceviruses, the similarity showed that about $94.82-99.00 \%$ identities among eight SCSMV isolates and 64.62\% identity with TriMV (Table 3). The CP protein of SCSMVTHA showed $94.72-98.93 \%$ identities among eight SCSMV isolates while it showed only $48.48 \%$ identity with TriMV.

The comparison of THA-NP3 with potyviruses causing mosaic diseases in sugarcane (SCMV, SrMV, MDMV, JGMV) showed less similarity with 29.01-29.38\% (nt) and 17.49-18.33\% (aa) identities (Table 3). Thus, THANP3 was a distinct virus genus separated from those of genus Potyvirus infecting sugarcane.

\subsection{Analysis of the Complete CP Gene}

The RT-PCR products using the primers, SCS-NIb-CP: F and SCS-NIb-CP: R revealed 1094 bp of the partial sequence of the polyprotein and 3'UTR. Sequence analysis revealed that the complete CP gene contained 846 nucleotides which encoded 281 amino acid residues. In this study, we investigated the genetic variability of the complete CP region (846 nts, 281 aa) of the 58 Thai SCSMV isolates; 36 isolates of which, were obtained from 14 farmers' fields; and 22 isolates of which, were obtained from three germplasm collection fields (Table 2). A nucleotide sequence comparison showed that the 36 isolates from different farmers' fields shared $86.17-100 \%$ identities while they shared 86.05-99.29\% identities to SCSMV isolates from other countries. The 22 isolates from germplasm shared $86.52-100 \%$ identities and $85.70-99.29 \%$ identities to the isolates from other countries. The CP gene of Thai SCSMV isolates shared only 60.28-63.71\% identities to the isolate of TriMV (NC_012799) which was used as an outgroup for construction of a phylogenetic tree.

The amino acid sequences revealed 96.09-100\% identities among the 36 isolates from collected farmers' fields while they shared $94.31-100 \%$ identities to the isolates from other countries. The 22 germplasm isolates from collected germplasm shared 94.66-100\% identities among each other, while they shared 93.24-100\% identities to the isolates from other countries. In addition, the CP gene of Thai SCSMV isolates shared 47.69-48.40\% identities when compared to the isolate of TriMV. The amino acid sequence alignment of all isolates from Thailand and other isolates from other countries revealed more variation at the amino acid position 1-31 of $\mathrm{N}$-terminal region and the core region, including C-terminus, were more conserved.

\subsection{Phylogenetic Relationships of SCSMV Based on the CP Sequences}

Phylogenetic relationships of the CP gene (846 nts) from 58 Thai SCSMV isolates (Table 2) and 27 SCSMV isolates from other countries were determined using a maximum-likelihood method. The CP sequences from Thai SCSMV isolates clustered in four well defined variant groups (Figure 4). Two sub-groups, which were designated as sub-groups $1 \mathrm{~A}$ and $2 \mathrm{~A}$, contained 38 isolates from Thailand, 9 isolates from China, 2 isolates from Japan, 1 isolate from Indonesia, 2 isolates from India and the unique variant from the isolate GK76-4 (Figure 4). The second major group consisted of 2 sub-groups, $1 \mathrm{~B}$ and $2 \mathrm{~B}$ which represented the isolates from germplasms in Thailand, India and China (Figure 4). The second sub-group, 2B contained only the isolates from collected germplasm in Thailand (Figure 4). These results suggested that Thai SCSMV isolates from different farmers' fields were more closely related to the isolates from China while the isolates from collected germplasm were closely related to the isolates from India and Pakistan (Figure 4).

Table 3. Identity percentages of complete genome sequence comparison between THA-NP3 isolate and the isolates from other countries, including potyviruses causing mosaic diseases in sugarcane

\begin{tabular}{|c|c|c|c|c|c|c|c|c|c|c|c|c|}
\hline protein name virus isolate & PAK & JP1 & JP2 & ID & TPT & IND671 & AP & TrimV & $\mathrm{SCMV}$ & SrMV & MDMV & JGMV \\
\hline whole genome $\left(9781 \mathrm{nt}^{\mathrm{a}}\right)$ & 81.83 & 97.78 & 97.84 & 97.73 & 94.80 & 81.39 & $\mathrm{na}^{\mathrm{c}}$ & 52.40 & 29.24 & 29.01 & 29.38 & 29.17 \\
\hline Polyprotein $\left(3130 a^{b}\right)$ & 95.27 & 98.98 & 98.98 & 98.98 & 98.40 & 94.38 & na & 50.38 & 18.33 & 17.49 & 18.14 & 17.65 \\
\hline P1 (358 aa) & 95.25 & 98.32 & 98.60 & 98.60 & 98.04 & 88.37 & na & 38.92 & 9.84 & 9.84 & 11.17 & 10.11 \\
\hline HC-Pro (470 aa) & 90.85 & 98.51 & 98.51 & 98.72 & 98.30 & 90.64 & na & 45.11 & 14.95 & 15.15 & 15.76 & 14.34 \\
\hline P3 (330 aa) & 95.15 & 99.09 & 99.09 & 99.39 & 98.18 & 96.06 & na & 34.94 & 9.81 & 9.81 & 9.26 & 10.90 \\
\hline 6K1 (49 aa) & 93.88 & 100 & 100 & 100 & 87.50 & 91.84 & na & 50.00 & 13.04 & 10.14 & 15.94 & 8.06 \\
\hline $\mathrm{CI}(656 \mathrm{aa})$ & 96.95 & 99.24 & 99.09 & 99.24 & 97.71 & 96.95 & na & 59.15 & 24.26 & 23.96 & 24.70 & 21.88 \\
\hline $6 \mathrm{~K} 2(48 \mathrm{aa})$ & 100 & 100 & 100 & 97.92 & 92.16 & 100 & 100 & 49.02 & 8.57 & 10.00 & 8.57 & 7.86 \\
\hline NIa-VPg (198 aa) & 96.97 & 98.48 & 98.48 & 98.48 & 94.12 & 97.98 & 95.45 & 22.27 & 22.01 & 20.57 & na & 22.49 \\
\hline NIa-Pro (238 aa) & 97.48 & 100 & 100 & 100 & 93.70 & 94.96 & 95.80 & 44.12 & 18.42 & 16.17 & 19.55 & 16.23 \\
\hline $\mathrm{NIb}$ (502 aa) & 95.02 & 99.00 & 99.00 & 98.80 & 97.04 & 94.82 & 97.01 & 64.62 & 32.29 & 32.66 & 31.38 & 33.64 \\
\hline CP (281 aa) & 95.73 & 98.58 & 98.93 & 98.58 & 95.47 & 94.72 & 96.80 & 48.48 & 14.91 & 12.86 & 12.99 & 14.41 \\
\hline
\end{tabular}

GenBank accession no. of the virus isolates are the followings: SCSMV-PAK: GQ388116 (Pakistan), 
SCSMV-JP1: JF488064 (China), SCSMV-JP2: JF488065 (China), SCSMV-ID: JN163911 (China), SCSMV-TPT: GQ246187 (India), SCSMV-IND671: JN941985 (India), SCSMV-AP: Y17738 (India), TriMV: NC_012799 (USA), SCMV: NC_003398 (China), SrMV: NC_004035 (China), MDMV: NC_003377 (Bulgaria), JGMV: NC_003606 (unknown; direct submission).

\subsection{Recombination Analysis of the CP Gene}

Using RDP seven algorithms, four recombinant isolates, namely GK76-4, M55, CB671-1 and GROC7 were detected (Table 4). The recombinant isolate GK76-4 had two recombination sites, nt 1-196 and nt 694-846 (Table 4). The recombinant isolate GK76-4 was distributed from the major parental isolate (FUD12-10) and the minor parental isolate (GRT2007-091). Another recombinant isolate, namely GROC7 (Table 4) had only one recombination site (nt 562-798) which was contributed by the major parental isolate (GRT2007-091) and the minor parental isolate (FUD12-8).

The recombinant isolate (M55) from China was distributed from the major parental isolate (GRT2007-091) and the minor parental isolate (PAK) while the recombinant isolate (CB671-1) from India was distributed from the major parental isolate from Thailand (FUD10-7) and the minor parental isolate from India (IND671). The recombination sites of M55 and CB671-1 were similar (Table 5). These results confirmed that the recombination occurred in the CP coding region among SCSMV isolates from different geographical regions, and sugarcane varieties in the presence of four recombinant isolates, GK76-4, GROC7, M55 and CB671-1 (Table 4).

\subsection{Phylogenetic Networks of Thai SCSMV Isolates}

The splits networks based on the alignment of the CP gene of 58 Thai SCSMV isolates revealed that the recombination events occurred among Thai SCSMV isolates that divided Thai SCSMV isolates into two major network groups (Figure 5). The recombinant isolate GK76-4 shared with these two network groups suggested that recombination occurred between the virus isolates from the collected farmers and germplasm fields. Nine SCSMV isolates (AP, TPT, IND671, JP1, JP2, ID, M55, CB671-1 and PAK) with likely to be the recombinant were selected for splits network analysis with 58 Thai SCSMV isolates. The splitstree based on the selected 67 isolates exhibited two major network groups (Figure 5). JP1, JP2, ID, TPT and AP isolates shared the same network group with the collected farmer isolates. The second network group consisted of 4 isolates, CB671-1, M55, IND671 and PAK that shared the same network with the collected germplasm isolates (Figure 5).

Table 4. Recombination events detected in the CP coding region of SCSMV isolates by using RDP4 (version 4.5)

\begin{tabular}{|c|c|c|c|c|c|c|c|c|c|c|c|}
\hline \multirow[t]{2}{*}{ Event no. } & \multirow[t]{2}{*}{ Recombinant isolate } & \multirow[t]{2}{*}{ Recombination site (nt) } & \multirow{2}{*}{$\begin{array}{l}\text { Major } \\
\text { parent }\end{array}$} & \multirow{2}{*}{$\begin{array}{l}\text { Minor } \\
\text { parent }\end{array}$} & \multicolumn{7}{|c|}{ Detection method* } \\
\hline & & & & & $\mathrm{R}$ & G & $\mathrm{B}$ & $\mathrm{M}$ & $\mathrm{C}$ & $\mathrm{S}$ & $\mathrm{T}$ \\
\hline 1 & GK76-4 & $1-196,694-846$ & FUD12-10 & GRT2007-091 & - & + & + & + & + & + & + \\
\hline 2 & M55 & $99-831$ & GRT2007-091 & PAK & - & - & - & + & + & + & + \\
\hline 3 & CB671-1 & $59-820$ & FUD10-7 & IND671 & + & - & + & + & + & + & + \\
\hline 4 & GROC7 & $562-798$ & GRT2007-091 & FUD12-8 & + & + & + & + & + & - & + \\
\hline
\end{tabular}

Note. *The methods used for recombination detection are the followings, R: RDP, G: GENECONV, B: Bootscan, M: MaxChi, C: Chimaera, S: SiScan and T: 3Seq, + represents the recombination was found and - represents the recombination was not found. 


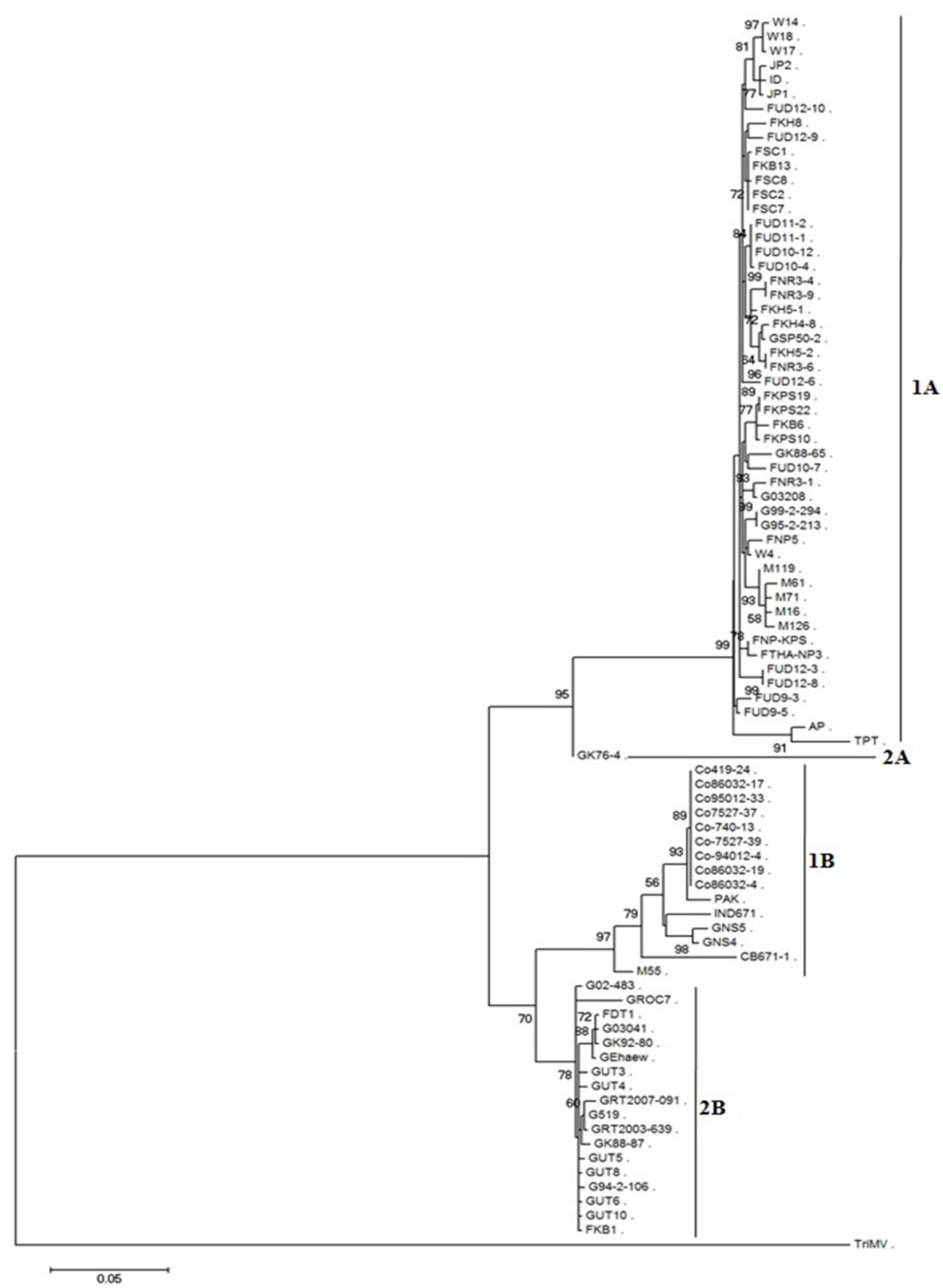

Figure 4. Maximum-likelihood tree based on the aligned CP nucleotide sequences of the 58 Thai SCSMV isolates and the 27 SCSMV isolates from other countries

The 13 SCSMV isolates from China are the following: M16 (JQ954718), M126 (JQ954701), M119 (JQ954719), M55 (JQ954717), M61 (JQ954716), M71 (JQ954714), W14 (JQ954700), W17 (JQ954699), W18 (JQ954698), W4 (JQ954720), ID (JF488066), JP1 (JF488064) and JP2 (JF488065). The 13 SCSMV isolates from India are the followings: Co419-24 (AM749404), Co7527-37 (AM749409), Co7527-39 (AM749410), Co740-13 (AM749398), Co86032-17 (AM920684), Co86032-19 (AM920685), Co86032-4 (AM920678), Co94012-4 (AM920678), Co95012-33 (AM749407), CB671-1 (DQ421788), IND671 (JN941985), AP (Y17738), TPT 
(GQ246187), one SCSMV isolate from Pakistan (GQ388116) and an outgroup, TriMV (NC_012799).

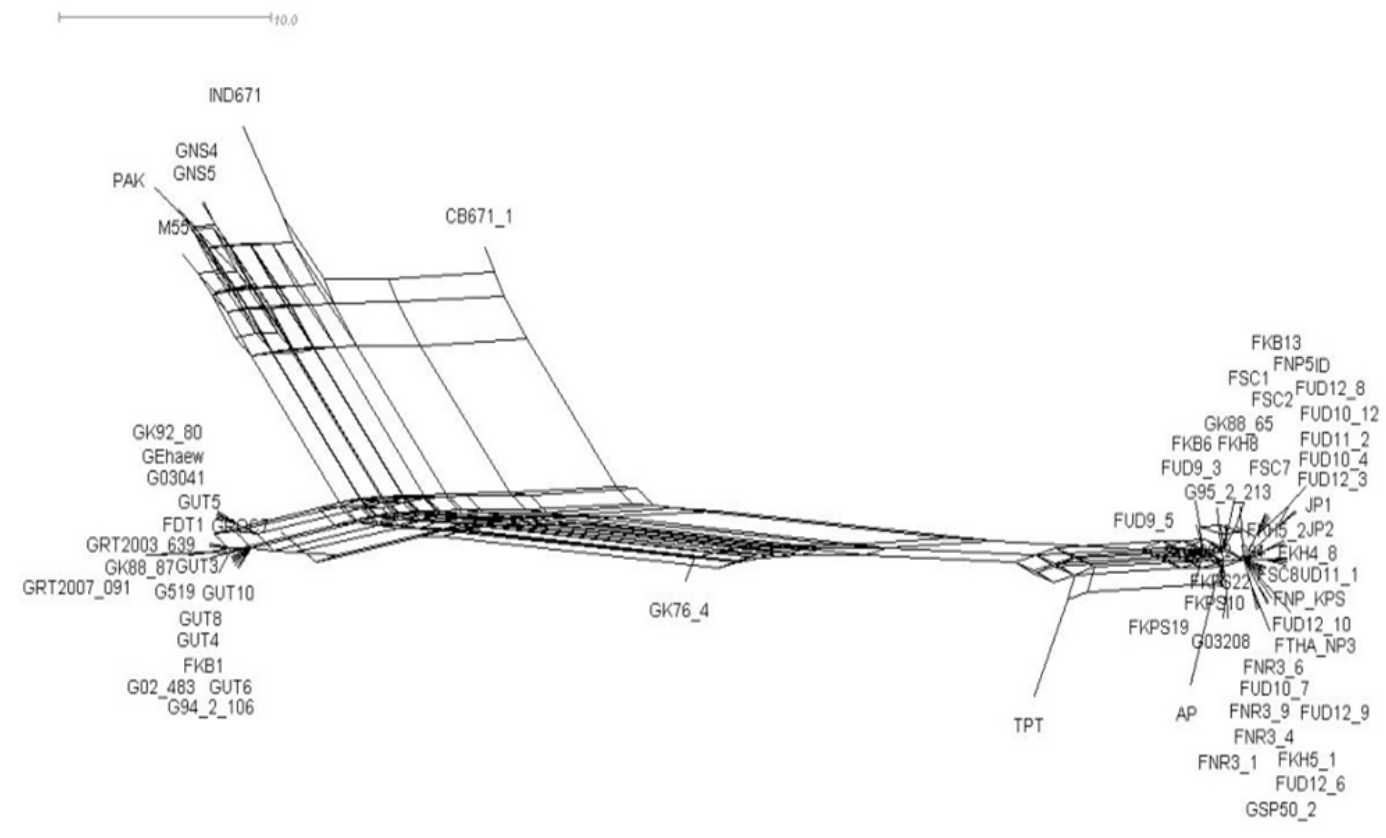

Figure 5. Phylogenetic networks of SCSMV isolates based on analysis of the CP coding sequences

The CP coding sequences from the 67 SCSMV isolates (58 Thai isolates and 9 isolates from other countries) were analyzed using the median network in SplitsTree4. The 9 SCSMV isolates are the followings: ID (JF488066), JP1 (JF488064), JP2 (JF488065), PAK (GQ388116), IND671 (JN941985), AP (Y17738), TPT (GQ246187), M55 (JQ954717), CB671-1 (DQ421788).

\section{Discussion}

Yellow streak mosaic is a typical symptom of streak mosaic disease in sugarcane caused by Sugarcane streak mosaic virus (SCSMV). In addition, the mosaic symptoms in sugarcane are associated with several viruses such as Sugarcane mild mosaic virus (SCMMV), Sugarcane striate mosaic associated virus (SCSMaV), Sugarcane mosaic virus (SCMV) and Sorghum mosaic virus (SrMV). The typical symptoms and host ranges are similar among these viruses (Chen, Chen, \& Adams, 2002). In this study, host range tests on plant species in genus Poaceae including sorghum cv. UT325B and the commercial corn cv. Tender 58 were investigated by mechanical inoculation. The typical symptoms of yellow streak mosaic were also exhibited on the inoculated sorghum and corn at 15 and $5 \mathrm{dpi}$, respectively (Figure 1c-d). These exhibited streak mosaic symptoms on the inoculated sorghum and corn were similar to those symptoms caused by SCMV that reported as potyvirus causing mosaic diseases in sugarcane, corn and sorghum in Thailand (Gemechu, 2004). These infected plants also confirmed for the presence of SCSMV infection by RT-PCR and the results revealed the presence of SCSMV-CP gene. Thus, we strongly confirmed that yellow streak mosaic symptom in these sugarcane leaves was caused by SCSMV, as previously reported by Chatenet et al. (2005).

The disease surveys from 2010 to 2014 revealed that the incidence of SCSMV was widespread across the major sugarcane growing areas in 5 provinces and the germplasm collection fields. The sugarcane variety groups maintained at the germplasm collection fields such as UT3, UT4, UT5, UT6, UT8 and UT10 were found to be more frequently infected with SCSMV. Than other sugarcane varieties such as K76-4, K88-65 and K88-87. More widespread observation of SCSMV in many sugarcane fields might be facilitated by mechanical transmission such as cutting knives but insect vectors are still uncertain. Our survey suggested that the commercial sugarcane varieties including germplasm collections were widely infected with SCSMV.

In this study, we selected the virus isolate THA-NP3 derived from sugarcane with unknown variety for complete genomic sequencing (Figure 1a). The complete genome sequence of THA-NP3 was successfully assembled from 11 overlapping sequences by using a set of primers designed in this study (Table 1). All cleavage sites of THA-NP3 proteins and the position of their amino acids were almost identical to those of SCSMV isolates PAK, 
ID, JP1, JP2 and TPT except for the isolate, IND671 which contained 3131 amino acid residues of the polyprotein. Nucleotide sequence comparison among seven complete genome isolates (THA-NP3, PAK, ID, JP1, JP2, IND671 and TPT) revealed more genetic variations in the P1, HC-Pro and CP genes. These three proteins revealed more genetic variation among SCSMV isolates originally from different sugarcane varieties (Bagyalakshmi et al., 2012; He et al., 2013).

Based on gene sequence variability, Thai SCSMV isolates were divided into two distinct groups (Figure 4), which were the group containing isolates from farmers' fields and another group of isolates from germplasm collection fields. However, some virus isolates obtained from farmers' fields were clustered in the same group with germplasm isolates. These results suggested that the variation of the $\mathrm{CP}$ gene occurred among various sugarcane varieties but was not associated with the geographical origin of the isolate.

Network analysis of the 58 Thai SCSMV isolates also confirmed that the recombination events occurred in the $\mathrm{CP}$ coding region among the virus isolates from different fields and germplasms (Figure 5). More evidence from the recombination detection by RDP4 revealed two recombinant isolates, GK76-4 and GROC7 (Table 4). A previous study reported that the recombinant isolate from China, CB671-1, was distributed from the parents, W23 $\times$ IND671, and three recombinant isolates (CB740, CB9217-1 and S-8) were distributed from the same parents, THA-NP3 $\times$ CB671-1 (He et al., 2013). In this study, we found that two recombinant isolates from China (CB671-1 and M55) were distributed from the parents, FUD10-7×IND671 and GRT2007-091×PAK, respectively. These results suggest that the recombination events occurred in the $\mathrm{CP}$ gene among the virus isolates from Thailand, China and India. More results have been reported that the recombination events occurred throughout the HC-Pro gene of SCSMV but not in the P1 gene (Bagyalakshmi et al., 2012; He et al., 2013). Recombination events have been reported as the evolutionary history of single-stranded RNA genome such as Turnip mosaic virus (TuMV), in the P1, HC-Pro, P3, CI, 6K2, VPg, NIa-Pro, NIb and CP genes, except for 6K1 gene (Ohshima et al., 2007). The recombinant isolate (GK76-4) obtained in this study was found to have two recombination sites which occurred in the variable $\mathrm{N}$-terminal region and the conserved sequence at the $\mathrm{C}$-terminal regions of the $\mathrm{CP}$ gene (Table 4).

In conclusion, our research indicates that the genetic base of hosts, including biological background, was an important factor for viral genetic variation and differentiation in SCSMV populations. This is the first report on the incidence of SCSMV in the commercial sugarcane varieties and the germplasm collections in Thailand. These results will assist sugarcane varieties improvement, screening and breeding for the virus resistant varieties.

\section{Acknowledgements}

This project was supported by the Center for Agricultural Biotechnology, Center of Excellence on Agricultural Biotechnology (AG-BIO/PERDO-CHE), Department of Plant Pathology, Kasetsart University, Kamphaeng Saen Campus and National Research Council of Thailand. We would also like to thank Assoc. Prof. Dr. Prasert Chatwachirawong and Assoc. Prof. Dr. Ratana Tongwongkit for their provision of sugarcane germplasm collections.

\section{References}

Bagyalakshmi, K., Parameswari, B., Chinnaraja, C., Karuppaiah, R., Kumar, V. G., \& Viswanathan, R. (2012). Genetic variability and potential recombination events in the HC-Pro gene of Sugarcane streak mosaic virus. Archives of Virology, 157, 1371-1375. http://dx.doi.org/10.1007/s00705-012-1297-8

Chandran, V., \& Gajjeraman, P. (2015). Molecular diversity analysis of Pretty Interesting Potyviridae ORF $(P I P O)$ coding region in Indian isolates of Sugarcane streak mosaic virus. Sugar Tech, http://dx.doi.org/10.1007/s12355-015-0376-z

Chatenet, M., Mazarin, C., Girard, J. C., Fernandez, E., Gargani, D., Rao, G. P, ... Rott, P. (2005). Detection of Sugarcane streak mosaic virus in sugarcane from several Asian countries. Proc ISSCT, 25, 656-662. Retrieved from http://www.issct.org

Chen, J., Chen, J., \& Adams, M. J. (2002). Characterisation of potyviruses from sugarcane and maize in China. Archives of Virology, 147, 1237-1246. http://dx.doi.org/10.1007/s00705-001-0799-6

Chiemsombat, P., Prammanee, S., \& Pipattanawong, N. (2014). Occurrence of Telosma mosaic virus causing passion fruit severe mosaic disease in Thailand and immunostrip test for rapid virus detection. Crop Protection, 63, 41-47. http://dx.doi.org/10.1016/j.cropro.2014.04.023

Chung, B. Y. W., Miller, W. A., Atkins, J. F., \& Firth, A. E. (2008). An overlapping essential gene in the Potyviridae. Proc Natl Acad Sci USA, 105, 5897-5902. http://dx.doi.org/10.1073/pnas.0800468105 
Damayanti, T. A., \& Putra, L. K. (2011). First occurrence of Sugarcane streak mosaic virus infecting sugarcane in Indonesia. Journal of General Plant Pathology, 77, 72-74. http://dx.doi.org/10.1007/s10327-010-0285-7

Gemechu, A. L. (2004). Variations Among Isolates of Sugarcane mosaic virus in Thailand (Doctoral's thesis, Kasetsart University, Nakhon Pathom, Thailand). Retrieved from http://lib.ku.ac.th

He, Z., Li, W., Yasaka, R., Huang, Y., Zhang, Z., Ohshima, K., \& Li, S. (2013). Molecular variability of Sugarcane streak mosaic virus in China based on an analysis of the P1 and CP protein coding regions. Archives of Virology, 159, 1149-1154. http://dx.doi.org/10.1007/s00705-013-1854-9

Hema, M., Sreenivasulu, P., \& Savithri, H. S. (2002). Taxonomic position of sugarcane streak mosaic virus in the family Potyviridae. Archives of Virology, 147, 1997-2007. http://dx.doi.org/10.1007/s00705-002-0851-1

Huson, D. H., \& Bryant, D. (2006). Application of phylogenetic networks in evolutionary studies. Molecular Biology and Evolution, 23, 254-267. http://dx.doi.org/10.1093/molbev/msj030

Kasemsin, P., Chiemsombat, P., \& Hongprayoon, R. (2011). New virus disease of sugarcane caused by Sugarcane streak mosaic virus. Proceedings of Thailand research symposium, 46-52. National Research Council of Thailand, Bangkok. Retrieved from http://www.rlc.nrct.go.th

Li, W., He, Z., Li, S., Huang, Y., Zhang, Z., Jiang, D., ... Luo, Z. (2011). Molecular characterization of a new strain of Sugarcane streak mosaic virus (SCSMV). Archives of Virology, 156, 2101-2104. http://dx.doi.org/10.1007/s00705-011-1090-0

Martin, D. P., Murrell, B., Golden, M., Khoosal, A., \& Muhire, B. (2015). RDP4: Detection and analysis of recombination patterns in virus genomes. Virus Evolution, 1, 1-5. http://dx.doi.org/10.1093/ve/vev003

Ohshima, K., Tomitaka, Y., Wood, J. T., Minematsu, Y., Kajiyama, H., Tomimura, K., \& Gibbs, A. J. (2007). Patterns of recombination in Turnip mosaic virus genomic sequences indicate hotspots of recombination. Journal of General Virology, 88, 298-315. http://dx.doi.org/10.1099/vir.0.82335-0

Parameswari, B., Bagyalakshmi, K., Viswanathan, R., \& Chinnaraja, C. (2013). Molecular characterization of Indian Sugarcane streak mosaic virus isolate. Virus Genes, 46, 186-189. http://dx.doi.org/10.1007/s11262-012-0827-5

Putra, L. K., Kristini, A., Achadian, E. M., \& Damayanti, T. A. (2014). Sugarcane streak mosaic virus in Indonesia: distribution, characterization, yield losses and management approaches. Sugar Tech, 16, 392-399. http://dx.doi.org/10.1007/s12355-013-0279-9

Srinivas, K. P., Subba Reddy, Ch. V., Ramesh, B., Lava Kumar, P., \& Sreenivasulu, P. (2010). Identification of a virus naturally infecting sorghum in India as Sugarcane streak mosaic virus. European Journal of Plant Pathology, 127, 13-19. http://dx.doi.org/10.1007/s10658-010-9580-6

Tamura, K., Stecher, G., Peterson, D., Filipski, A., \& Kumar, S. (2013). MEGA6: Molecular evolutionary genetics analysis version 6.0. Molecular Biology and Evolution, 30, 2725-2729. http://dx.doi.org/10.1093/molbev/mst197

Thongpaiyai, C., Wongpraneekul, A., \& Chatwachirawong, P. (2012). Genetic diversity and relationships among commercial sugarcane varieties in Thailand. Khon Kaen Agriculture Journal, 3, 60-67. Retrieved from http://www.ag2.kku.ac.th

Verwoerd, T. C., Dekker, B. M., \& Hoekema, A. (1989). A small-scale procedure for the rapid isolation of plant RNAs. Nucleic Acids Research, 17, 2362. http://dx.doi.org/10.1093/nar/17.6.2362

Viswanathan, R., Balamuralikrishnan, M., \& Karuppaiah, R. (2008). Characterization and genetic diversity of Sugarcane streak mosaic virus causing mosaic in sugarcane. Virus Gene, 36, 53-564. http://dx.doi.org/10.1007/s11262-008-0228-y

Xu, D. L., Zhou, G. H., Xie, Y. J., Mock, R., \& Li, R. (2010). Complete nucleotide sequence and taxonomy of Sugarcane streak mosaic virus, member of a novel genus in the family Potyviridae. Virus Genes, 40, 432-439. http://dx.doi.org/10.1007/s11262-010-0457-8

\section{Copyrights}

Copyright for this article is retained by the author(s), with first publication rights granted to the journal.

This is an open-access article distributed under the terms and conditions of the Creative Commons Attribution license (http://creativecommons.org/licenses/by/3.0/). 